\title{
Venture Capital Backed Growth
}

\author{
Christian KeuschnigG* \\ University of St.Gallen (IFF), CEPR and CESifo
}

January 2002

\begin{abstract}
The paper proposes a simple equilibrium model of venture capital, entrepreneurship and innovation. Venture capitalists not only finance but also advise startup entrepreneurs and thereby add value to new firms. The paper demonstrates how a productive and active VC industry boosts innovation driven growth.

Keywords: Venture capital, double moral hazard, innovation, growth. JEL-Classification: D82, G32, O16, O40.

Address: University of St.Gallen, IFF-HSG, Varnbuelstrasse 19, CH-9000 St.Gallen, Switzerland. Phone: +41-71-224 -2520 /-3085, Fax: -2670, http://www.iff.unisg.ch, Email: christian.keuschnigg@unisg.ch
\end{abstract}

*A previous version of the paper was presented at the CEPR workshop on "Dynamic Aspects of Taxation" at Tilburg university, September 2000, and at Universities of Helsinki and Saarbrücken. I appreciate helpful comments by seminar participants and, in particular, by my discussant S. van Wijnbergen. 


\section{Introduction}

Creation of innovative young firms is an important source of innovation and growth. It is often claimed that venture capital (VC) makes young firms grow faster, create more value and generate more employment than other start-ups (European Venture Capital Association 1996). It is widely claimed among economists that the existence of a sophisticated VC industry is a major factor behind America's ability to encourage and sustain technological innovation and growth. Empirical research in the U.S. has shown indeed that VC can importantly enhance the ability of new firms to create wealth and jobs. ${ }^{1}$ According to Kortum and Lerner (2000), VC backed firms are more innovative and produce more and more valuable patents. They are faster in developing their products and introducing them to market. They have a higher rate of executive turnover, reflecting faster managerial professionalization (Hellmann and Puri 2000, 2001). It seems that the existence of an active VC sector can show up in superior macroeconomic performance. Recently, Wasmer and Weil (2000) econometrically investigated panel data of 20 OECD countries over the years 1986 to 95. They found that an increase in the GNP share of venture capital by 0.075 would reduce the short-run unemployment rate by 0.25 percentage points while the long-run effect would amount to a reduction of .9 to 2.5 percentage points. ${ }^{2}$ The success of the U.S. VC industry is not easily duplicated in other countries, however. The empirical study by Bottazzi and Da Rin (2001) suggests that European VC has grown vigorously in terms of volume invested but apparently had not much influence on growth and employment of portfolio firms. They conclude that the quality of European VC is a more urgent issue than sheer quantity.

This raises the question what the real contribution of VC exactly is, and how incentives in VC investing are determined. Venture Capitalists (VCs) carefully screen firms, structure contracts to strengthen incentives, and monitor firms (Kaplan and Strömberg

\footnotetext{
${ }^{1}$ Gompers and Lerner $(1999,2001)$ summarize recent research on venture capital.

${ }^{2}$ The value of 0.075 corresponds to one standard deviation of the GNP share of VC. In Europe, this would amount to an increase in the GNP share of VC from 0.38 to $0.46 \%$.
} 
2001). They add value to new firms, promote their professionalization, and induce them to behave more aggressively. It is often stated that the U.S. with an active VC sector is faster in adopting new technologies. Kortum and Lerner (2000) estimate indeed that a dollar of VC seems about three times more potent in stimulating patenting than a dollar of traditional corporate R\&D. They also concluded that by 1998, venture funding accounted for about $14 \%$ of U.S. innovative activity.

This paper aims at modeling the real effects of VC. We ask how an active VC sector with experienced and sophisticated investors may contribute to faster innovation driven growth. ${ }^{3}$ Our model explores how the joint inputs of both entrepreneurs and VCs determine the prospects of start-up firms. While entrepreneurs contribute the key technological idea, they tend to be commercially inexperienced. VCs support the firm with managerial advice that draws on their industry knowledge and commercial expertise. We study analytically how certain structural parameters determine the quality of VC finance and how this affects entrepreneurship and innovation in general equilibrium. For example, Gompers and Lerner (1999, p.4) pointed to the fact that the skills needed for successful VC investing are difficult and time-consuming to acquire and are likely to be an important constraint in the development of an active $\mathrm{VC}$ industry that is able to promote the professionalization of new firms. We thus study how an exogenous increase in investor sophistication raises the quality of $\mathrm{VC}$ financing and how this translates into a faster rate of innovation in general equilibrium. We also study the consequences of certain other parameters relating to the inputs of both entrepreneurs and VCs to start-up firms.

In developing a model of $\mathrm{VC}$ with double moral hazard, we explain not only the incentives of entrepreneurs but also those of VCs. The analysis importantly draws on Repullo and Suarez (1999), Casamatta (1999), Lülfesmann (1999), and Schmidt (2001), to mention only a few. This literature in finance, however, is mostly confined to an analysis of contracts and the associated incentives for agents' efforts but fails to address the real effects of VC in equilibrium [see the survey by Gompers and Lerner (2001)]. This

\footnotetext{
${ }^{3}$ In this paper, "growth" refers to effects on levels rather than growth rates.
} 
paper, in contrast, offers a comparative static analysis of the effects of exogenous shocks on managerial advice by VCs, profit sharing, start-up entrepreneurship and innovation in general equilibrium. The next section introduces the analytical framework. It extends the two period overlapping generations model pioneered by Diamond (1965) by including occupational choice between entrepreneurs and workers and double moral hazard in the relation between entrepreneurs and VC firms. Section 3 derives the comparative static effects of parameters that relate to managerial productivity, intangible effort cost, and capital requirements in start-up investment. The final section concludes.

\section{The Model}

An overlapping generations model of entrepreneurship and innovation is proposed. Production of a final good uses specialized capital goods which are introduced by innovative start-up firms. Entrepreneurs have ideas but no own capital. In addition, they are commercially inexperienced. Venture capitalists (VCs) have managerial knowhow and access to capital. They collect savings and finance a portfolio of start-up firms. They not only provide finance but also add value in giving managerial advice. The success of the company in developing a marketable capital good critically depends on the effort of the entrepreneur but is further enhanced by the managerial support of the VC. The efforts of both the entrepreneur and the VC are not contractible, giving rise to double moral hazard. If the firm successfully matures to production stage, a specialized capital good is produced in the next period and supplied to final goods producers. The present value of the monopolistic profits must, in equilibrium, cover the expected start-up cost of the firm. The paper embeds this sort of innovation finance in a general equilibrium model of overlapping generations. The subsequent sections first present consumption and savings decisions of workers and entrepreneurs and then turn to the production side. With these preliminaries, we then analyze the creation and financing of start-up firms that design new specialized capital goods. The final subsection closes the model and explains how the equilibrium innovation rate is determined. 


\subsection{Consumption}

It is assumed that agents are risk neutral, live for two periods and consume a final consumption good which is the numeraire. Although they are identical ex ante, occupational risk introduces intragenerational heterogeneity ex post. Once risk is resolved, first period income $y_{t}^{i}$ of an agent $i \in[0,1]$ is known. Being a worker yields a safe income while an entrepreneur's income is risky as it will depend on the success of the company. Given first period income, the savings decision determines life-cycle consumption of agent $i$ according to $C_{1, t}^{i}=y_{t}^{i}-S_{t}^{i}$ and $C_{2, t+1}^{i}=R_{t+1} S_{t}^{i}$. The risk free interest factor $R_{t+1}$ is one plus the market rate of interest. After eliminating savings to derive the intertemporal budget constraint, the life-cycle consumption problem is

$$
U_{t}^{* i}=\max \left\{u_{0} \cdot\left(C_{1, t}^{i}-h_{t}^{i}\right)^{1-m}\left(C_{2, t+1}^{i}\right)^{m}+\lambda_{t}^{i}\left[y_{t}^{i}-C_{1, t}^{i}-C_{2, t+1}^{i} / R_{t+1}\right]\right\}
$$

where $u_{0} \equiv m^{-m}(1-m)^{-(1-m)}$ and $h_{t}^{i}=\beta e_{t}^{i}$ is the utility cost of the effort $e_{t}^{i}$ that the agent must put up in the first period to earn income. ${ }^{4}$ Effort reduces the utility of first period consumption as is usual in intertemporal models of labor supply. ${ }^{5}$ Effort cost of workers is normalized to zero. The effort choice of entrepreneurs is explained later. We first solve for indirect utility, conditional on a given level of effort. The first order conditions imply $C_{2, t+1}^{i} / R_{t+1}=\frac{m}{1-m}\left(C_{1, t}^{i}-h_{t}^{i}\right)$ which is substituted into the intertemporal budget constraint to yield first period consumption, $C_{1, t}^{i}-h_{t}^{i}=(1-m)\left(y_{t}^{i}-h_{t}^{i}\right)$. Indirect utility is, thus,

$$
U_{t}^{* i}=U\left(R_{t+1}, y_{t}^{i}-h_{t}^{i}\right)=\left(R_{t+1}\right)^{m} \cdot\left(y_{t}^{i}-h_{t}^{i}\right)
$$

The linear homogeneous specification of preferences implies risk neutrality. Furthermore, savings is a constant fraction $m$ of effort adjusted income,

$$
S_{t}^{i}=y_{t}^{i}-C_{1, t}^{i}=m \cdot\left(y_{t}^{i}-h_{t}^{i}\right)
$$

\footnotetext{
${ }^{4}$ As a convention, all parameters are defined positive, $\beta, m>0$.

${ }^{5}$ In Auerbach and Kotlikoff (1987), for example, leisure and consumption are traded off in each period while welfare in retirement depends on consumption. Also real business cycle models first solve for a within period allocation of consumption and leisure before the intertemporal allocation is determined.
} 


\subsection{Production}

The final good is the numeraire. Following Romer (1987), production is assumed to use labor and quantities $x^{j}$ of the $j \in\left[1, N_{t}\right]$ varieties of capital, to give a final output

$$
Y_{t}=Y_{0} \cdot L_{t}^{\alpha} \int_{0}^{N_{t}}\left(x_{t}^{j}\right)^{1-\alpha} d j, \quad 0<\alpha<1, \quad Y_{0}=(1-\alpha)^{-(1-\alpha)}
$$

The normalization of factor productivity $Y_{0}$ is for simplicity only. From cost minimization, the own price elasticity of demand for variety $j$ is $-\left(d x^{j} / x^{j}\right) /\left(d q^{j} / q^{j}\right)=1 / \alpha$, where $q^{j}$ is the price of variety $j$. Each intermediate capital good is protected by a patent and supplied by a single firm which has started up in the previous period and has successfully matured to production stage. This firm faces a perceived price elasticity of demand equal to $1 / \alpha$. With a large number of competing varieties, cross price elasticities may be neglected as is usual in models of monopolistic competition. One unit of the specialized capital good is produced from $\kappa$ units of the final numeraire good. An intermediate goods producer thus derives profits equal to

$$
\pi_{t}^{j}=\left(q_{t}^{j}-\kappa\right) \cdot x_{t}^{j}, \quad \kappa=1-\alpha
$$

where again the choice of the input output coefficient serves to simplify the solution. Maximizing profits subject to a downward falling demand curve with own price elasticity of $1 / \alpha$, a producer sets an output price and obtains profits equal to

$$
q_{t}^{j}=\frac{1}{1-\alpha} \cdot \kappa=1, \quad \pi_{t}^{j}=\alpha \cdot x_{t}^{j}
$$

Price $q=1$ is a mark-up over unit cost $\kappa$, resulting in a profit margin of $\alpha$ per unit. Since demand elasticity and technology are uniform, intermediate goods production is symmetric, making output of the final good equal to $Y=Y_{0} N L^{\alpha} x^{1-\alpha}$. Using $N q x=$ $(1-\alpha) Y,(6)$ and $Y_{0}$ as in (4), equilibrium outputs and the wage rate can be related to the number of capital goods $N_{t}$ and labor $L_{t}$,

$$
x_{t}=(1-\alpha) L_{t}, \quad Y_{t}=N_{t} L_{t}, \quad W_{t}=\alpha N_{t}
$$

where $W_{t} L_{t}=\alpha Y_{t}$ was used to obtain the wage equal to the marginal product of labor. 


\subsection{Venture Capital}

It is assumed that capital fully depreciates and capital goods become obsolete after one period of production. The life-cycle of a firm thus consists of a start-up period in $t$ and a production period in $t+1$. A firm that successfully matures in period $t$, starts production next period and generates a present value of profits equal to

$$
V_{t}=\frac{\pi_{t+1}^{X}}{R_{t+1}}
$$

Once the firm survives the start-up period, it can be sold to other investors, if a market for young firms exists, or it can be introduced in the stock market by an initial public offering. In any case, the firm is valued at a price $V_{t}$ as in (8).

Firms are started by entrepreneurs who have technological knowhow but are commercially inexperienced. Starting a firm is very risky. We assume that the firm succeeds to develop a useful capital good with probability $0<p_{t}<1$ but fails with probability $1-p_{t}$. If the firm fails, it never reaches the production stage and all start-up investment is lost. Young innovative firms fail not only because of technological risks but also because entrepreneurs are often commercially inexperienced. Their survival chances can be significantly enhanced if they can enlist the managerial advice of an experienced VC. Taking account of this, we specify the success probability as

$$
p_{t}=e_{t} \cdot p\left(a_{t}\right), \quad p(a)=\varepsilon \cdot \frac{a^{1-\theta}}{1-\theta}, \quad 0<\theta<1, \quad e_{t} \in\{0,1\}
$$

where $a_{t}$ denotes the VC's advice and $e_{t}$ the entrepreneur's effort. According to this specification, the entrepreneur's effort is critical. The firm can never succeed without the entrepreneur's effort and due diligence, $e_{t}=0$. It succeeds with probability $p_{t}>0$ only if her effort is high, $e_{t}=1$. In this case, however, the VC may add value and boost the firm's survival chance according to $p\left(a_{t}\right)$. Managerial advice is assumed to be subject to decreasing returns to scale, $p^{\prime}>0>p^{\prime \prime}$. The functional form in (9) is for convenience where the parameter $\varepsilon$ indicates the VC's commercial knowhow and experience. A more experienced and knowledgable $\mathrm{VC}$ will achieve, with the same number of consulting hours, 
a higher success rate than a less experienced one. ${ }^{6}$ Neither the effort of the entrepreneur nor the advice of the VC are verifiable and contractible.

VC investing involves a sequence of events. First, the VC contacts a number of entrepreneurs. $^{7}$ Second, the VC proposes to buy a share $1-s$ in the firm at a price $Q=B+K$ that covers the physical start-up cost $K$ plus an upfront payment $B$. The entrepreneur accepts this offer or otherwise opts to earn a safe worker's salary. Third, after the deal is finalized, both the entrepreneur and VC expend effort to develop the firm. Effort choice is conditional on the incentives provided by the terms of contract. Finally, risk is resolved and firms which have successfully developed a capital goods variety, are sold at a price $V$. Revenues are distributed according to the equity stakes $s$ and $1-s$. The model is solved backwards.

Anticipating how the terms of the proposed contract determine incentives for subsequent effort, the VC structures the deal to maximize, ${ }^{8}$

$$
\begin{gathered}
\Omega=\max _{s, B} e p(a)(1-s) V-Q-\gamma a \quad \text { s.t. } \quad Q=B+K, \\
\text { (a) } P C^{E}: e p(a) s V+B-\beta e \geq W, \\
\text { (b) } I C^{E}: p(a) s V-\beta \geq 0, \\
\text { (c) } I C^{F}: e p^{\prime}(a)(1-s) V=\gamma .
\end{gathered}
$$

The VC buys a stake $1-s$ in the firm for a price $Q$. Since the entrepreneur has no own wealth, the price must cover at least the start-up cost $K$. The VC expects a profit per deal of $\pi^{F}=e p(a)(1-s) V-Q$. Advising the portfolio company also involves an intangible effort cost $\gamma a$ per project. ${ }^{9}$ The VC would naturally want to acquire a large stake for a small price. However, the deal must be sufficiently attractive to the entrepreneur to make

\footnotetext{
${ }^{6}$ Parameters must be chosen such that the equilibrium level of advice implies $0<p_{t}<1$.

${ }^{7}$ We do not model the screening of business plans but rather concentrate on the value added by VCs after the deal is negotiated.

${ }^{8}$ We suppress the time index, except when needed for clarity.

${ }^{9}$ In assuming this effort cost linear, the number of portfolio firms is not determined by individual optimization but is implied in equilibrium by a free entry condition. With convex effort cost, Kanniainen and Keuschnigg (2001) derive an optimal number of portfolio companies per VC.
} 
her willing to start a firm. The contract must thus satisfy the participation constraint (10.a). Being employed in industry would earn a safe wage $W$. If she instead opts for entrepreneurship, she makes an initial capital gain $B=Q-K$ on her venture by selling the share $1-s$ at a price in excess of the start-up cost. When the firm matures to production stage, it can be sold at a price $V$ of which the entrepreneur retains a share $s$, yielding a further expected capital gain equal to $p s V$. In total, expected income, less the effort cost $h=\beta e$ expended on developing the firm to maturity, must compensate at least for the foregone wages in industry. ${ }^{10}$

The solution follows backward induction. When agents decide about effort, the terms of contract are fixed and initial investments are sunk. At this stage, the VC can influence only the part ep $(a)(1-s) V-\gamma a$ of expected profit where the share $1-s$ has been fixed in the preceding stage. Taking the effort of the entrepreneur as given, she chooses a level of advice as in (10.c). The entrepreneur, in turn, chooses effort among discrete alternatives $e \in\{0,1\}$ whichever yields a higher return $e \cdot[p(a) s V-\beta]$, giving rise to the incentive constraint (10.b). Efforts are complimentary. The VC advises only if the entrepreneur's effort is high, but wastes no time when the entrepreneur is shirking. The entrepreneur's incentive to put up high effort increases when the $\mathrm{VC}$ advises more intensively and, thereby, raises the survival fortunes of the firm.

When the VC structure the deal, she anticipates how the terms of contract affect the entrepreneur's and her own incentives in the effort stage. Since she would collect no revenue at all if the entrepreneur's effort is low, she must always cede a profit share high enough such that the entrepreneur's incentives are preserved. Since her profits decline with $s,{ }^{11}$ the VC wants to keep the entrepreneur's share as small as possible such that $I C^{E}$ is binding. Conditions (10b,c) thus simultaneously determine the equity share and

\footnotetext{
${ }^{10} \mathrm{We}$ assume that agents also derive income $\Pi$ per capita from ownership of VC firms. The participation constraint requires, in fact, that utility from entrepreneurship is higher than utility from a worker's career. Noting (2), the constraint is $R^{m} \cdot(p s V+B-\beta+\Pi) \geq R^{m} \cdot(W+\Pi)$, and reduces to (10.a) after eliminating common terms.

${ }^{11}$ Using (10.c), we have $d \Omega / d s=-p V$.
} 
the level of managerial support such that $e=1$. With $I C^{E}$ binding, the entrepreneur's participation constraint reduces to $B \geq W$. With $s$ and $a$ already fixed, the VC will buy the share $1-s$ at the smallest possible price $Q=B+K$ by squeezing the upfront payment $B$ until the entrepreneur's participation constraint becomes binding as well. The profit maximizing solution to the VC's investment problem is, thus,

$$
\begin{aligned}
& \text { (a) } P C^{E}: \quad B=W, \\
& \text { (b) } I C^{E}: p(a) s V=\beta, \\
& \text { (c) } I C^{F}: p^{\prime}(a)(1-s) V=\gamma .
\end{aligned}
$$

Note, in particular, the recursive structure of the problem. Conditions (11b,c) determine $a(V, \cdot)$ and $s(V, \cdot)$ in terms of the firm's price or stock market value $V$ and parameters.

\subsection{Equilibrium}

The paper studies symmetric equilibria. Competitive VC firms finance and advise more companies until profit opportunities vanish. A "zero profit" condition must thus hold in equilibrium,

$$
\pi^{F}=p(a)(1-s) V-(K+W)=\gamma a, \quad \Pi=\pi^{F} E
$$

where $Q=K+W$. A VC firm must make positive profits in equilibrium to compensate for intangible effort cost.

With each entrepreneur starting only one firm, the number of projects that must be financed each period, is equal to the number of entrepreneurs. By the law of large numbers, only a fraction $p$ succeeds in the aggregate while a fraction $1-p$ fails. The number of mature capital goods firms next period is, thus,

$$
N_{t+1}=p\left(a_{t}\right) E_{t}
$$

Agents are either entrepreneurs or workers, with a total mass of unity,

$$
L+E=1 \text {. }
$$


We solve for equilibrium in terms of a savings investment identity. A worker earns $y^{L}=W+\Pi$ where $\Pi$ denotes income per capita from ownership of VC firms, see (12). An entrepreneur obtains a total capital gain of $s V+B$ if the firm is successful, but only $B$ if it fails. Expected or average income, including dividends from VC firms, is $y^{E}=p s V+B+\Pi$. By (11a) and (14), aggregate income of young agents is

$$
y=\int_{0}^{1} y^{i} d i=y^{L} L+y^{E} E=p s V E+W+\Pi .
$$

According to (3), savings depends on income adjusted for effort cost. As the participation constraint (10a) must hold with equality, income of an entrepreneur less effort cost is $y^{E}-\beta=W+\Pi$. Aggregating (3) and using (12), economy wide savings is

$$
S=m \cdot \int_{0}^{1}\left(y^{i}-h^{i}\right) d i=m \cdot(W+\gamma a E) .
$$

Using (11a,b), the zero profit condition (12) implies investment spending equal to

$$
p(a) V E=(K+W+\beta+\gamma a) E \equiv I .
$$

Equating (16) and (17), the savings investment identity $S=I$ implies an equilibrium number of entrepreneurs, ${ }^{12}$

$$
m W=\Phi \cdot E, \quad \Phi \equiv \beta+K+W+(1-m) \gamma a
$$

The model is now solved as follows. The incentive constraints $(11 \mathrm{~b}, \mathrm{c})$ give $s(V)$ and $a(V)$. Using this together with (11a), $W=B$, the zero profit condition in (12) determines the equilibrium stock market price of the firm as a function of the wage rate, $V(W)$. In free entry equilibrium, the consulting activity ultimately depends on the wage as well, $a(V(W))$. The savings investment identity in (18) thus yields the equilibrium number of entrepreneurs, or new start-ups, $E(W)$. According to (7), the wage is predetermined by the number of preexisting capital goods. Using all this information, we obtain from (13) a difference equation in the number of capital goods,

$$
N_{t+1}=p\left(a\left[V\left(W_{t}\right)\right]\right) E\left(W_{t}\right), \quad W_{t}=\alpha N_{t} \quad \Rightarrow \quad N_{t+1}=\phi\left(N_{t}\right) .
$$

\footnotetext{
${ }^{12}$ By Walras' Law, the $S=I$ condition also implies market clearing of final goods, see Appendix A.
} 
Appendix $\mathrm{C}$ discusses existence of a stationary equilibrium. The stability properties will be determined in section 3.3.

\section{Venture Capital Backed Growth}

We consider transitional rather than long-run growth. ${ }^{13}$ How do innovation and growth depend on the parameters that determine the quality of VC finance? We are particularly interested in the comparative static effects of changes in the VC's managerial productivity $\varepsilon$ and her effort cost $\gamma$, the entrepreneur's effort $\operatorname{cost} \beta$, and the size of the start-up investment $K$. A higher value of $\varepsilon$ indicates increased knowhow, experience and industry knowledge of VC firms, making consulting activity more effective. Any given time input by the VC then adds more value to the firm and achieves a higher success probability. We have argued that the entrepreneur contributes the technological innovation and business idea while the VC adds commercial knowhow. Larger managerial effort cost $\gamma$ might thus reflect a more difficult business environment under rapidly changing market conditions which presumably makes the commercial input more critical for the success of the firm. An increased effort cost $\beta$ of entrepreneurs, in contrast, might result from greater risks of technological development, requiring a larger effort to sustain the prospects of the project. Finally, product development and innovation might simply become more capital intensive and require a larger physical investment $K$.

We now provide a comparative static analysis of $\mathrm{VC}$ backed growth by log-linearizing the model at an initial position of stationary equilibrium. This exercise reveals how various shocks affect the quality of VC finance, entrepreneurship, and innovation. The analysis also provides the required stability result. Since we start from a position of stationary equilibrium, the initial values of all variables are constant and time autonomous. The hat notation, e.g. $\hat{a}_{t}=d a_{t} / a$, indicates percentage changes relative to constant initial values after a shock occurs. All shocks are assumed permanent.

\footnotetext{
${ }^{13}$ Endogenous growth can presumably be modeled as in Grossman and Yanagawa (1993).
} 


\subsection{Equilibrium VC Investing}

We first turn to the nature of VC investment in free entry, zero profit equilibrium. By (9), the VC's consulting input together with the productivity of managerial advice determines the success probability of the firm,

$$
\hat{p}_{t}=\hat{\varepsilon}+(1-\theta) \hat{a}_{t}
$$

The constraints $(11 b, c)$ show how the incentives to help with managerial advice and the propensity for entrepreneurial effort depend on the profit sharing rule and other parameters. In fact, (11b) gives the minimum profit share $s$ that just makes the entrepreneur to put up her critical effort. When the expected venture return increases, either because of a higher firm value $V$ or a higher success chance $p$, a smaller share suffices to compensate the entrepreneur for her effort, or human capital contribution. When her effort cost increases, she requires, of course, a higher equity share. This, in turn, implies a lower share for the $\mathrm{VC}$ which diminishes incentives for advice:

$$
\begin{aligned}
& \text { (a) } \theta \hat{a}_{t}=\hat{\varepsilon}-\frac{s}{1-s} \hat{s}_{t}+\hat{V}_{t}-\hat{\gamma}, \\
& \text { (b) } \hat{s}_{t}=\hat{\beta}-\hat{V}_{t}-(1-\theta) \hat{a}_{t}-\hat{\varepsilon} .
\end{aligned}
$$

These constraints are mutually interdependent and simultaneously fix advice and incentive compatible profit sharing,

$$
\begin{aligned}
& \text { (a) } \hat{a}_{t}=\frac{1}{\theta-s}\left[\hat{V}_{t}+\hat{\varepsilon}-(1-s) \hat{\gamma}-s \hat{\beta}\right], \\
& \text { (b) } \hat{s}_{t}=-\frac{1-s}{\theta-s}\left[\hat{V}_{t}+\hat{\varepsilon}-(1-\theta) \hat{\gamma}-\theta \hat{\beta}\right]
\end{aligned}
$$

where $\theta>s$ by the following stability argument. ${ }^{14}$ Starting with an exogenous shock to her effort $\operatorname{cost} \beta$, the entrepreneur requires in (21b) a higher share $s$ to reward her effort. When the financier is left with a smaller share $1-s$, she feels less interest in the firm and advises less, see (21a). As the success probability falls and the project becomes more

\footnotetext{
${ }^{14}$ The appendix states in (A.6) a condition for $\theta>s$ which is always fulfilled if the informational friction indicated by the entrepreneur's unobserved effort $\operatorname{cost} \beta$ is not too high. See the discussion in (29) for an upper bound on $\beta$.
} 
risky, the entrepreneur demands an even higher equity share to reward her effort which again erodes the VC's share, and so on. This cycle converges when $\theta>s$.

VCs are assumed to be competitive. As they fund more start-ups, venture returns $V$ eventually tend to be exhausted which eliminates profits from $\mathrm{VC}$ investing. We thus compute the competitive return by imposing a free entry zero profit condition. To this end, we log-linearize VC profits. Starting from a zero profit position, we define $\hat{\Omega} \equiv d \Omega$, and set the logarithmic differential of (10) equal to zero. By the envelope theorem, we may ignore the change in advice, and arrive at $\hat{\Omega}=(1-s) p V(\hat{V}+\hat{\varepsilon})-s p V \hat{s}-Q \hat{Q}-a \gamma \hat{\gamma}=0$. Replacing $a \gamma$ by (A.5) and subsequently $Q$ by (A.3), we get

$$
\hat{V}=\frac{s}{1-s} \hat{s}+\theta \hat{Q}+(1-\theta) \hat{\gamma}-\hat{\varepsilon}
$$

An increase in effort cost $\gamma$ or a higher purchase price $Q$ require higher venture returns to retain profitability in VC investing. An increase in the entrepreneur's minimum required equity share, leaving a smaller share to the VC, reduces profits and similarly requires a higher return $V$ to restore a break even. A higher success rate, in contrast, allows for lower returns. Substituting the entrepreneur's incentive compatible profit share from (22b) shows how the return in free entry equilibrium adjusts to shocks,

$$
\hat{V}=s \hat{\beta}+(1-\theta) \hat{\gamma}+(\theta-s) \hat{Q}-\hat{\varepsilon}
$$

Increases in effort cost of entrepreneurs or VCs, or a higher initial equity investment $Q$ on account of increased start-up cost $K$ or better outside opportunities of entrepreneurs $W$, all require higher equilibrium venture returns to retain profitability of VC investments. These returns feed back on the level of advice and the entrepreneur's equity share in zero profit equilibrium. Substituting into $(22)$ gives $^{15}$

$$
\hat{a}=\hat{Q}-\hat{\gamma}, \quad \hat{s}=(1-s)(\hat{\beta}-\hat{Q})
$$

\footnotetext{
${ }^{15}$ As a check, $\hat{a}_{t}$ and $\hat{s}_{t}$ are directly obtained by log-linearizing (A.3) and (A.5) which already reflect the zero profit condition. Substituting (25) into the linearized version of (11b), i.e. (21b), yields (24). The more roundabout derivation in the text helps to interpret the economic adjustment mechanism.
} 
where the $\mathrm{VC}$ must pay a price $Q$ for the acquired equity share that covers the initial investment outlays and the entrepreneur's outside opportunities,

$$
\hat{Q}=\xi \hat{W}+(1-\xi) \hat{K}, \quad \xi \equiv \frac{W}{W+K}, \quad 0<\xi<1 .
$$

\subsection{Start-up Investment}

The number of start-up firms is equal to the number of entrepreneurs who are able to obtain financial support. VCs are financial intermediaries who collect savings and allocate them to fund investment projects. Equilibrium entrepreneurship or start-up investment thus follows from the savings investment identity in (18), $m W=\Phi E$. Using (A.5) to replace $\gamma a$, we obtain

$$
\Phi=\beta+[m+(1-m) / \theta] Q, \quad \hat{\Phi}=\sigma \cdot \hat{\beta}+(1-\sigma) \cdot \hat{Q}, \quad \sigma \equiv \frac{\beta}{\Phi}=\frac{\beta E}{m W} .
$$

Using (18), we denote by $0<\sigma<1$ the share of entrepreneurial effort compensation $\beta E$ in net investment cost $m W$ (net of the savings out of $\mathrm{VC}$ profits). Note that $\beta=s p V$ is the expected profit income that must be ceded to entrepreneurs to compensate them for their effort. With this information, and using (26), we now compute from (18) how the number of entrepreneurs adjusts,

$$
\hat{E}=\hat{W}-\hat{\Phi}=[1-(1-\sigma) \xi] \hat{W}-(1-\sigma)(1-\xi) \hat{K}-\sigma \hat{\beta}, \quad 0<\sigma<1,
$$

where the coefficient of $\hat{W}$ is positive, but smaller than one. On the one hand, a higher wage improves the entrepreneur's outside opportunities and, thus, raises start-up cost $Q$ which retards investment. On the other hand, higher wages raise net savings available for investment finance and thereby accommodate a larger amount of entrepreneurial investment. On net, higher wages boost entrepreneurship. Higher physical capital requirements, or higher effort costs on the part of entrepreneurs, inflate start-up investment cost and thereby depress entrepreneurship. 


\subsection{Innovation}

Innovation is measured by the number $N$ of specialized capital goods. The gains from specialization determine factor productivity and wages in general equilibrium as in (7). Innovation dynamics follows from (19), $N_{t+1}=p\left(a_{t}\right) E_{t}$, and is determined by the number of successful start-up firms. Innovation thus reflects entrepreneurship $E_{t}$ which is driven by the propensity of agents to start a firm rather than opt for a safe industry career. It also reflects the contribution by VCs whose managerial advice promotes the professionalization and commercial expertise of entrepreneurs and raises their survival chance $p_{t}$. In the absence of VC finance and with no managerial support available to start-up entrepreneurs, the success rate $p$ would be an exogenously fixed parameter. ${ }^{16}$ The endogeneity of advice acts like a magnifier or multiplier on innovation activity if advice and entrepreneurship turn out to be strategic complements in equilibrium.

By (25), (26) and (28), both managerial support and the number of start-ups are tied to the wage rate. By (7), the wage rate is proportional to the number of specialized capital goods. Linearization of (19) yields $\hat{N}_{t+1}=\hat{\varepsilon}+(1-\theta) \hat{a}_{t}+\hat{E}_{t}$ or, after substituting (25, $26,28)$ and noting $\hat{W}_{t}=\hat{N}_{t}$ by $(7)$,

$$
\hat{N}_{t+1}=[1-(\theta-\sigma) \xi] \hat{N}_{t}-(\theta-\sigma)(1-\xi) \hat{K}-(1-\theta) \hat{\gamma}-\sigma \hat{\beta}+\hat{\varepsilon}, \quad \theta>\sigma .
$$

For innovation dynamics to be stable, the coefficient of $\hat{N}_{t}$ must be smaller than one which requires $\theta>\sigma=\beta / \Phi$ as a stability condition. Stability is necessarily fulfilled if $\beta$ is sufficiently small. The cost $\beta$ of the unobserved effort is a natural measure of the degree of informational friction. Appendix $\mathrm{C}$ shows that $\beta=0$ characterizes a first best equilibrium where the stability condition is automatically fulfilled. With moral hazard, a critical upper bound of $\beta$ to satisfy stability is derived from (18) and (A.5). By the definition of $\sigma$ and (18), the stability condition is $\theta>\sigma=\beta /[\beta+Q+(1-m) \gamma a]$. Upon substituting (A.5) and rearranging, this is equivalent to $[1-m(1-\theta)] Q /(1-\theta)>\beta$. In equilibrium, the wage rate and, therefore, $Q=W+K$ depend on parameter $\beta$. Since $K$

\footnotetext{
${ }^{16}$ With a slight increase in complexity, we could write the success probability in (9) as $p=p_{0}+p_{1}(a)$.
} 
is a lower bound for $Q$, this condition is necessarily fulfilled for $\beta$ sufficiently small. Since the square bracket is positive but smaller than unity, this stability condition a fortiori implies $Q /(1-\theta)>\beta$, and therefore $\theta>s$ in (A.6) and (22).

The number $N$ of capital goods firms which were created in the preceding period, is a predetermined stock variable. Due to gains from specialization, a larger number of firms corresponds to a larger degree of innovation and factor productivity. To study innovation dynamics, we consider the consequences of an exogenous shock $\hat{N}_{t}>0$ which corresponds to an exogenous increase in wages, $\hat{W}_{t}=\hat{N}_{t}$ according to (7). To compensate for improved outside opportunities in industry, entrepreneurs demand a larger price $\hat{Q}_{t}=\xi \hat{W}_{t}$ for selling a share $1-s$ in their firm. The equity investment of VCs increases which cuts into their profits. They will exit the industry and fund fewer projects until venture returns increase by enough to restore profitability and allow them to break even in free entry equilibrium, see (23). Higher venture returns strengthen incentives for managerial advice and also allow to cut the entrepreneur's minimum profit share that prevents shirking as in (22). ${ }^{17}$ In the end, a higher wage boosts venture returns and advice and allow for smaller profit participation of entrepreneurs in zero profit equilibrium as is stated in (24) and (25). Finally, higher wages augment aggregate savings that is available to finance startup investment but also raise the total cost (including the cost of compensating effort) of starting new firms. The net effect is positive and allows to finance a larger number of start-up entrepreneurs, $\hat{E}_{t}=[1-(1-\sigma) \xi] \hat{W}_{t}$ in (28). According to (29), innovation thus increases not only because more firms get started $\left(\hat{E}_{t}>0\right)$, but also because a larger fraction of them succeeds on account of more intensive VC support $\left(\hat{a}_{t}>0\right)$.

Whenever an exogenous shock to the industry displaces the equilibrium innovation locus given in (19), the local stability condition noted above assures that the economy converges to a long-run stationary equilibrium in the neighborhood of the initial steady state position. After the adjustment process is completed, the long-run consequences are

\footnotetext{
${ }^{17}$ Note that the initial equity investment $Q$ is sunk when agents choose effort. For this reason, $Q$ does not directly affect advice and incentive compatible profit sharing in (22).
} 
just a magnification of the short-run effects,

$$
\hat{N}=\frac{1}{(\theta-\sigma) \xi}[\hat{\varepsilon}-(\theta-\sigma)(1-\xi) \hat{K}-(1-\theta) \hat{\gamma}-\sigma \hat{\beta}], \quad \theta>\sigma .
$$

Figure 1 illustrates transitional adjustment:

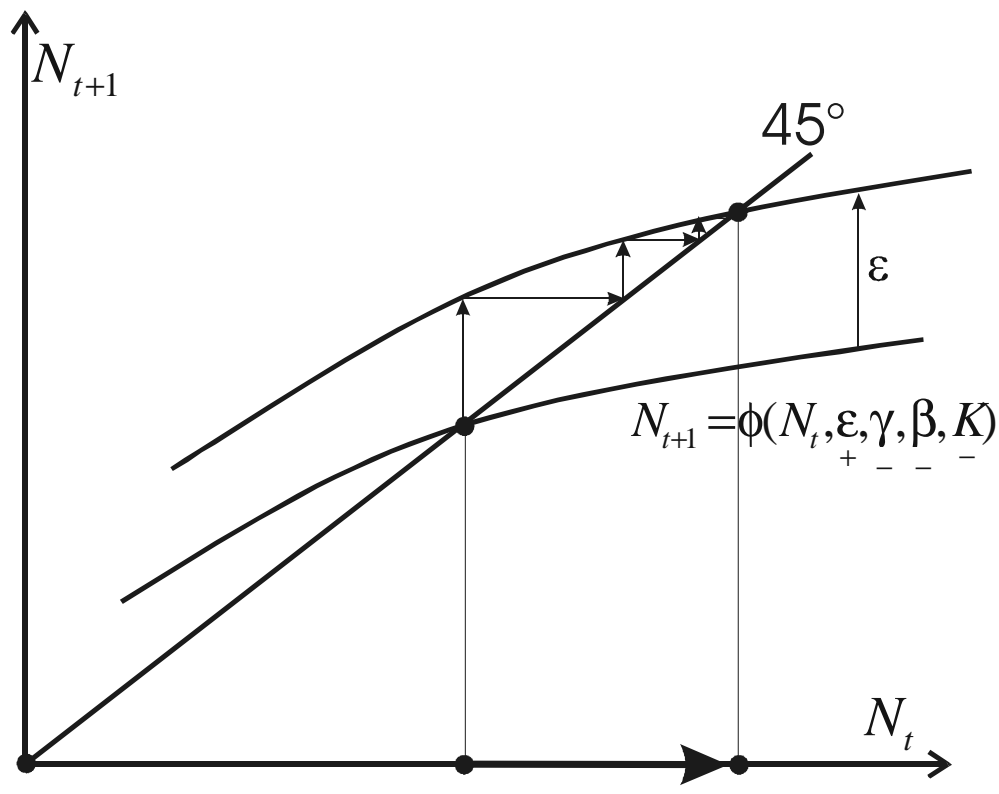

Fig. 1: Innovation Dynamics

\subsection{Comparative Statics}

The preceding analysis and figure 1 demonstrate how a permanent exogenous shock translates into prolonged transitional adjustment that just magnifies the short-run effects. It is thus sufficient to discuss only the short-run effects of various shocks where wages and the number of firms are predetermined.

Consulting Productivity: Suppose that knowhow and experience in the VC industry and, therefore, managerial productivity $\varepsilon$ improves permanently. When VCs are more sophisticated, the same time input into the consulting activity receives a higher marginal expected return which strengthens incentives for more active VC involvement. When VCs allocate more time to managerial support, and this time input is more productive, the success probability increases on both accounts. With a higher expected return on the 
project, a smaller profit share suffices to secure the entrepreneur's critical effort, leaving for the same price $Q$ a higher share to the VC. More investor sophistication boosts profits. As VCs expand their investment activities, venture returns will eventually decline until profit opportunities are exhausted. Lower returns diminish incentives for advice. In zero profit equilibrium, consulting hours thus remain the same (see 25) but they are more productive, giving $\hat{p}=\hat{\varepsilon}$ in (20). In the short-run, entrepreneurship does not adjust in (28) since neither wages nor start-up costs $Q$ are affected. Hence, supply and demand for investment funds remain the same, allowing to finance the same number of start-up entrepreneurs. Since the consulting input is more productive, a larger fraction of these entrepreneurs succeeds which boosts the short-run rate of innovation in $(29), \hat{N}_{t+1}=\hat{\varepsilon}$.

Innovation raises labor productivity and wages in subsequent periods. Reflecting improved opportunities in industry, VCs must pay a higher price to attract entrepreneurs and to obtain a share in the venture, see (26). Venture returns must increase in (23) to allow VCs to break even which stimulates managerial support and allows for a smaller profit share of entrepreneurs. Higher wages stimulate savings by more than they inflate investment costs (see 16-18). The net increase in funds allows to finance more start-up firms which further magnifies successful innovation in the long-run (see 28 and 29).

Managerial Effort Cost: Rapidly changing market conditions, red tape and other regulations might increase the VC's cost of providing finance and advice. With more costly managerial effort, VCs will obviously cut back on their consulting activity which raises start-up risk. With expected returns $p(a) V$ lower, entrepreneurs demand a higher profit share to compensate for their own critical effort which further destroys profitability in $\mathrm{VC}$ finance. In the end, venture returns $V$ in the competitive free entry equilibrium must be higher to allow break even (see 24) while the advisory support is less intensive as in (25). Note that the increase $\hat{\gamma}$ in the marginal cost of advice is exactly compensated by the reduction in the consulting activity to leave overall managerial effort cost $a \gamma$ unchanged, $\hat{a}+\hat{\gamma}=\hat{Q}=0$ in the short-run. With wages fixed, neither the overall start-up cost $\Phi$ per project nor the overall pool of available investment funds are affected whence 
the number of business start-ups remains constant as well, see (18), or the differential form in (28). Since advice per project is lower, a smaller fraction of the same number of start-ups is successful which results in a smaller rate of innovation. Subsequently, wages and entrepreneurship both decline.

Entrepreneurial Effort Cost: When starting a firm is perceived more costly by the entrepreneur, they must receive a larger equity share to secure their critical effort. At the same time, this also undermines the VC's incentive to get involved in the firm. Having to pay the same price for a smaller share in profits clearly subtracts from expected VC profits. When VCs cut back their investment activities, venture returns will eventually increase which restores again the incentives for advice. In free entry equilibrium, the entrepreneur retains a higher profit share, the $\mathrm{VC}$ supplies the same level of advice, and firm values are higher, see (24) and (25). Since the VC is able to acquire only a smaller equity stake for the same price $Q$, the overall start-up cost per project is higher by $\hat{\Phi}=\sigma \hat{\beta}$ in (27) while the available investment funds remain the same for a given short-run wage. The number of start-ups in (28) must decline when more costly projects have to be financed out of a given pool of funds. While the success rate is not affected in the short-run, innovation declines on account of a smaller number of start-ups, $\hat{N}_{t+1}=-\sigma \hat{\beta}$ in (29). Subsequently, the lower rate of innovation depresses labor productivity and erodes wages, causing a further reduction in consulting activity, entrepreneurship and innovation.

Capital Intensity of Start-ups: When business formation requires larger initial investment outlays $K$ per project, VCs need to inject a larger amount $Q$ of equity to get the firm started. Managerial advice and profit sharing are not directly affected since the initial investment outlays are already sunk when agents choose effort. Larger start-up cost, however, erodes VC profits which requires exit and a subsequent increase in venture returns to restore profitability. In zero profit equilibrium, firm values and advice are higher which, at the same time, requires a lower profit share for the entrepreneur, see (24) and (25). Depending on the share of physical capital expenditures $K$, total investment cost 
including intangible effort costs must increase, $\hat{\Phi}=(1-\sigma)(1-\xi) \hat{K}$. Since the supply of funds is fixed in the short-run with constant wages, it can finance only a smaller number of business start-ups. The economy consequently supports less innovation, leading to falling labor productivity, wages and a further decline in entrepreneurship in the future.

\section{Conclusions}

This paper proposed a simple equilibrium model of venture capital, entrepreneurship and innovation. While the entrepreneur contributes the key technological idea in starting up a new firm, the venture capitalist supports the firm with managerial advice which presumably draws on her extensive business experience and industry knowledge. The joint efforts of entrepreneurs and financiers are non-verifiable and are thus subject to double moral hazard. The model emphasizes the incentives of financiers to become actively involved with the firm. The analysis points to the fact that the experience and knowhow of VCs which determine their effectiveness in advising start-up firms, is a critical factor in determining the quality of VC finance, and can importantly enhance entrepreneurship and innovation in the economy.

The model is highly stylized and thereby cuts out important aspects of VC finance in real life. Only a small part of all start-ups actually attract VC finance. Nevertheless, the impact of the VC sector on the macroeconomy can be quite pronounced as Wasmer and Weil (2000) found in their econometric investigation. Apart from monitoring and advising, VCs carefully select their investments [see Kaplan and Strömberg (2001)], and mostly focus on innovative firms with high risk but high potential, leaving the rest to banks and other sources of finance. To endogenously explain how VCs and banks split the market is way beyond this paper. ${ }^{18}$ But even then, the value added contribution of

\footnotetext{
${ }^{18}$ See Strobel (2001), or Amit, Glosten and Muller (1990) for an early attempt. These authors rely on static partial equilibrium models and do not consider the implications for industry equilibrium. The analysis is complicated by the interaction between adverse selection and moral hazard problems. Azariadis
} 
VCs should importantly promote the performance of these firms as the empirical literature finds, and should be an significant determinant of innovation and growth as in this paper.

\section{Appendix}

A Final Goods Market: Multiplying (13) by $V_{t}$ and using (8) and (17) yields $I_{t} \cdot R_{t+1}=p\left(a_{t}\right) E_{t} V_{t} \cdot R_{t+1}=N_{t+1} \pi_{t+1}^{X}$. Future profits must cover current investment cost plus interest. From $I_{t}=S_{t}$, we thus obtain consumption of the old, $C_{2, t}=R_{t} I_{t-1}=\pi_{t}^{X} N_{t}$. For the same reason, consumption of the young is

$$
C_{1, t}=y_{t}-I_{t}=s_{t} p_{t} V_{t} E_{t}+W_{t}+\Pi_{t}-\left(Q_{t}+\beta+\gamma a_{t}\right) E_{t}=L_{t} W_{t}-K E_{t},
$$

where we first used (15) and (17), and then (11b), (12) and (14). Using (5),

$$
C_{t} \equiv C_{1, t}+C_{2, t}=L_{t} W_{t}-K E_{t}+q_{t} x_{t} N_{t}-\kappa x_{t} N_{t}=Y_{t}-K E_{t}-\kappa x_{t} N_{t}
$$

where $Y_{t}=W_{t} L_{t}+q_{t} x_{t} N_{t}$. The income identity or commodity balance follows after subtracting the cost of intermediates from gross final goods production. GDP equals consumption plus private, start-up investment,

$$
Y_{t}-\kappa x_{t} N_{t}=C_{t}+K E_{t}
$$

B Zero Profit Restrictions: From (9), we have $a p^{\prime}=(1-\theta) p$. Therefore, the $I C^{F}$-constraint $(11 \mathrm{c})$ implies

$$
\gamma a=(1-\theta)(1-s) p V
$$

Using this in the zero profit condition (12), and using (11b) as well, we have

$$
\theta(1-s) p V=Q, \quad \frac{1-s}{s}=\frac{Q}{\theta \beta}, \quad Q=K+W .
$$

and Chakraborty (1999) consider financial intermediation with adverse selection but without moral hazard in OLG models. They do not model any active contribution of financiers as is important in VC finance. 
With this result, we can explicitly compute the equity shares,

$$
s=\frac{\theta \beta}{\theta \beta+Q}, \quad 1-s=\frac{Q}{\theta \beta+Q} .
$$

Substituting (A.3) into in (A.2) gives an explicit solution for equilibrium advice,

$$
a=\frac{1-\theta}{\theta \gamma} Q
$$

Finally, use (A.4) to compute

$$
\theta-s=\theta \cdot \frac{Q-(1-\theta) \beta}{\theta \beta+Q}>0 \quad \Leftrightarrow \quad \frac{Q}{1-\theta}>\beta .
$$

C First Best: The stability condition noted in (29), $\theta>\sigma$, with $\sigma$ defined in (27), is guaranteed by assuming the agency $\operatorname{cost} \beta$ not too large. In fact, $\beta=0$ is possible, eliminates any problem of asymmetric information, and thus corresponds to a first best equilibrium. With $\beta=0, I C^{E}$ is not binding and is fulfilled even with $s=0$. In (A.4), $s \rightarrow 0$ for $\beta \rightarrow 0$. The VC thus buys the entire firm at a price $Q=B+K$ with $B=W$ equal to the entrepreneur's outside wage according to $P C^{E}$. With no unobserved effort cost, the entrepreneur's cooperation can be secured without profit sharing. With $\beta, s=0$, the VC's optimality condition is $p^{\prime}(a) V=\gamma$ and gives the first best level of managerial effort. ${ }^{19}$ With $\beta, s>0$, the VC must share the marginal returns of advice with the entrepreneur and, therefore, supplies less support than in the first best.

With $\beta, s=0$, the zero profit condition is $\theta p V=Q$, giving optimal advice $\gamma a=$ $(1-\theta) p V=\frac{1-\theta}{\theta} Q$. Using this, the S-I identity (18) yields $m W=E \cdot[Q+(1-m) \gamma a]$ or $m W=E \cdot[1-(1-\theta) m] \gamma a /(1-\theta)$ in the first best. Now we substitute the stationary version of (19), $W=\alpha N=\alpha p E$, and have $m \alpha p=[1-m(1-\theta)] \gamma a /(1-\theta)$. Using the functional form of $p$, the solution for $a$ in stationary equilibrium is

$$
a=\left[\frac{m \alpha \varepsilon / \gamma}{1-m(1-\theta)}\right]^{1 / \theta} \Rightarrow p=\frac{\varepsilon^{1 / \theta}}{1-\theta}\left[\frac{m \alpha / \gamma}{1-m(1-\theta)}\right]^{(1-\theta) / \theta}
$$

\footnotetext{
${ }^{19}$ The first best solution results from maximizing joint surplus $p(a) V-\gamma a-\beta-K-W$ which is the sum of $\Omega$ in (10) and the entrepreneur's surplus $s p(a) V-\beta+B-W$ in (10a).
} 
For any $m$, we can vary $\varepsilon$ or $\gamma$ to calibrate a reasonable success probability $p<1$. Given $a$ and $p$, we have $\gamma a \frac{\theta}{1-\theta}=Q$ from the preceding paragraph. Having determined $Q$, set $K$ such that a reasonable wage $W=Q-K$ obtains. Knowing the wage, rewrite the S-I identity $m W=E \cdot[Q+(1-m) \gamma a]$ to get the equilibrium number of entrepreneurs: ${ }^{20}$

$$
E=\frac{\theta m}{\theta m+1-m} \cdot \frac{W}{Q}<1
$$

The restriction $0<E<1$ is satisfied since both multiplicative terms are positive but less than one. A well defined, interior SS solution of the first best equilibrium with $\beta=0$ exists. By continuity, the same will hold for small but positive $\beta$.

\section{References}

[1] Amit, Raphael, Lawrence Glosten and Eitan Muller (1990), Entrepreneurial Ability, Venture Investments, and Risk Sharing, Management Science 36, 1232-1245.

[2] Auerbach, Alan J. and Laurence Kotlikoff (1987), Dynamic Fiscal Policy, Cambridge University Press.

[3] Azariadis, Costas and Shankha Chakraborty (1999), Agency Costs in Dynamic Economic Models, Economic Journal 109, 222-241.

[4] Bottazzi, Laura and Marco Da Rin (2001), Venture Capital in Europe: Euro.nm and the Financing of European Innovative Firms, Paper presented at 33rd Economic Policy Panel Meeting in Stockholm.

[5] Casamatta, Catherine (1999), Financing and Advising: Optimal Financial Contracts With Venture Capitalists, University of Toulouse, mimeo.

[6] Diamond, Peter A. (1965), National Debt in a Neoclassical Growth Model, American Economic Review 55, 1126-1150.

[7] European Venture Capital Association (1996), The Economic Impact of Venture Capital in Europe, a study by Coopers \& Lybrand for EVCA (http: \\www.bvca.org).

[8] Gompers, Paul A. and Josh Lerner (1999), The Venture Capital Cycle, Cambridge: MIT Press.

\footnotetext{
${ }^{20}$ With the same result, we could infer entrepreneurship also from (19), $W=\alpha p E$, instead of the S-I identity, since both restrictions have entered into (A.7).
} 
[9] Gompers, Paul A. and Josh Lerner (2001), The Venture Capital Revolution, Journal of Economic Perspectives 15, 145-168.

[10] Grossman, Gene M. and Noriyuki Yanagawa (1993), Asset Bubbles and Endogenous Growth, Journal of Monetary Economics 31, 3-19.

[11] Hellmann, Thomas and Manju Puri (2000), The Interaction between Product Market and Financing Strategy: The Role of Venture Capital, Review of Financial Studies, 13, 959-984.

[12] Hellmann, Thomas and Manju Puri (2001), Venture Capital and the Professionalization of Start-ups: Empirical Evidence, Journal of Finance, forthcoming.

[13] Kanniainen, Vesa and Christian Keuschnigg (2001), Start-up Investment With Scarce Venture Capital Support, CESifo WP No. 439.

[14] Kaplan, Steven N. and Per Strömberg (2001), Venture Capitalists as Principals: Contracting, Screening, and Monitoring, American Economic Review (Papers and Proceedings), 91, 426-430.

[15] Kortum, Samuel and Josh Lerner (2000), Assessing the Contribution of Venture Capital to Innovation, Rand Journal of Economics 31, 674-692.

[16] Lülfesmann, Christoph (1999), Start-up Firms, Venture Capital Financing, and Renegotiation, University of Bonn, mimeo.

[17] Repullo, Rafael and Javier Suarez (1999), Venture Capital Finance: A Security Design Approach, CEPR DP No. 2097.

[18] Romer, Paul (1987), Growth Based on Increasing Returns Due to Specialization, American Economic Review 77, 56-63.

[19] Schmidt, Klaus M. (2001), Convertible Securities and Venture Capital Finance, Munich, CESifo WP No. 217, revised.

[20] Strobel, Peter (2001), Marktsegmentierung zwischen Venture Capital und Banken, Saarbrücken: University of Saarland, unpublished PhD thesis.

[21] Wasmer, Etienne and Philippe Weil (2000), The Macroeconomics of Labor and Credit Market Imperfections, Bonn: IZA DP 179. 